Check for updates

Kent, UK

Cite this as: BMJ 2021;373:n1663 http://dx.doi.org/10.1136/bmj.n1663 Published: 29 June 2021

\section{Covid-19: Upgrading to FFP3 respirators cuts infection risk, research finds}

\author{
Jacqui Wise
}

Upgrading face masks to filtering face piece ( $\left.\mathrm{FFP}_{3}\right)$ respirators for healthcare workers on covid-19 wards produced a dramatic reduction in hospital acquired SARS-CoV-2 infections, according to research carried out at Addenbrooke's Hospital in Cambridge. ${ }^{1}$

The study, published as a preprint, has been welcomed by campaigners who have been calling on the government to ensure that healthcare workers are given better personal protective equipment (PPE).

For most of last year Cambridge University Hospitals NHS Foundation Trust followed national guidance that healthcare workers should use fluid resistant surgical masks as respiratory protective equipment unless aerosol generating procedures (AGPs) were being carried out when $\mathrm{FFP}_{3}$ respirators were advised.

Since the start of the pandemic the trust has been regularly screening its healthcare workers for SARS-CoV-2 even when asymptomatic. They found that healthcare workers on "red" covid-19 wards were at greater risk of infection than staff on "green" wards even when using the recommended protective equipment. So in December 2020 the trust implemented a change in policy so that staff on red wards wore $\mathrm{FFP}_{3}$ masks instead of fluid resistant surgical masks.

Before the change in policy, cases among staff were higher on covid-19 wards compared with non-covid-19 wards in seven out of eight weeks analysed. Following the change in protective equipment the incidence of infection on the two types of ward was similar. Of 609 positive results over the eight week study period, 169 were included in the study. Those excluded were healthcare workers who were not ward based or worked between different wards, non-clinical staff, and staff working in critical care areas.

The researchers developed a simple mathematical model to quantify the risk of infection for healthcare workers. This found that the risk of direct infection from working on a red ward before the change in policy was 47 fold greater than the corresponding risk from working on a green ward. While almost all cases on green wards were likely caused by infection in the community, cases on red wards at the beginning the study period were attributed mainly to direct, ward based exposure.

The model also suggested that the introduction of $\mathrm{FFP} 3$ respirators provided 100\% protection (confidence interval 31.3\%, 100\%) protection against direct, ward based covid infection.

The research was funded by Wellcome, the Addenbrooke's Charitable Trust, UK Research and
Innovations, and the NIHR Cambridge Biomedical Research Centre.

Study author, Chris Illingworth from the MRC Biostatistics Unit at the University of Cambridge, said, "Before the face masks were upgraded, the majority of infections among healthcare workers on the covid-19 wards were likely because of direct exposure to patients with covid-19. Once $\mathrm{FFP}_{3}$ respirators were introduced, the number of cases attributed to exposure on covid-19 wards dropped dramatically-in fact, our model suggests that $\mathrm{FFP}_{3}$ respirators may have cut ward based infection to zero."

Michael Weekes from the department of medicine at the University of Cambridge, added, "Our data suggest there's an urgent need to look at the PPE offered to healthcare workers on the frontline. Upgrading the equipment so that $\mathrm{FFP}_{3}$ masks are offered to all healthcare workers caring for patients with covid-19 could reduce the number of infections, keep more hospital staff safe, and remove some of the burden on already stretched healthcare services caused by absence of key staff because of illness.

The BMA, the Royal College of Nursing, and other professional bodies have been calling for some time for $\mathrm{FFP}_{3}$ masks to be provided more widely. In January 2021 FreshAir NHS, a group of frontline NHS workers, wrote an open letter to all UK governments requesting airborne mitigations to prevent infections in healthcare staff and reduce nosocomial infection risk to patients. ${ }^{2}$ In a BMJ Opinion piece, the group welcomed the new data, saying it provided yet more evidence of why the policy needs to change. ${ }^{3}$

Public Health England recently updated its guidance to oblige NHS organisations to assess the risk that covid-19 poses to staff and provide $\mathrm{FFP}_{3}$ respirators where appropriate and not just when AGPs are taking place. ${ }^{45}$ The update follows a review by the government's Scientific Advisory Group for Emergencies published in April which said that the decision to use $\mathrm{FFP}_{3}$ respirators should be based on a risk assessment that considers the interaction with a patient, the duration and proximity of exposure, whether there is good fitting and mask adherence, whether staff are routinely wearing eye protection, and whether patients wear masks. ${ }^{6}$

\footnotetext{
Ferris M, Ferris R, Workman C, et al. FFP3 respirators protect healthcare workers against infection with SARS-CoV-2.Authorea [Preprint]. 2021doi: 10.22541/au.162454911.17263721/v1.

2 Wise J. Covid-19: Doctors and nurses demand better PPE for wider range of procedures. BM/2021;372:n30. doi: 10.1136/bmj.n30 pmid: 33408072

3 Lawton T, Butler M, Peters C, et al. Use of airborne precautions for covid-19 in healthcare settings. BMJ Opinion. 28 June 2021. https://blogs.bmj.com/bmj/2021/06/28/use-of-airborne-precautions-forcovid-19-in-healthcare-settings.

4 Public Health England. Covid-19: guidance for maintaining services within health and care settings. 2020. www.gov.uk/government/publications/wuhan-novel-coronavirus-infection-prevention-and-control
} 
5 Torjesen I. Covid-19: PPE guidance is upgraded as evidence of airborne transmission grows. BMJ 2021;373:n1422. doi: 10.1136/bmj.n1422 pmid: 34078639

6 SAGE. Masks for healthcare workers to mitigate airborne transmission of SARS-CoV-2. 25 March 2021. www.gov.uk/government/publications/emg-masks-for-healthcare-workers-to-mitigateairborne-transmission-of-sars-cov-2-25-march-2021.

This article is made freely available for use in accordance with BMJ's website terms and conditions for the duration of the covid-19 pandemic or until otherwise determined by BMJ. You may use, download and print the article for any lawful, non-commercial purpose (including text and data mining) provided that all copyright notices and trade marks are retained. 